\section{Category}

Peptide Chemistry

\section{Key words}

dehydroalanine

aminofluoroacrylates

fluoro-Pummerer rearrangement

fluorodehydroalanine

H. ZHOU, W. A. VAN DER DONK* (UNIVERSITY OF ILLINOIS AT URBANA-CHAMPAIGN, USA) Synthesis of 2-Amino-3-fluoroacrylic Acid Containing Peptides Org. Lett. 2001, 3, 593-596.

\title{
Synthesis of Fluorodehydroalanine-Containing Peptides
}

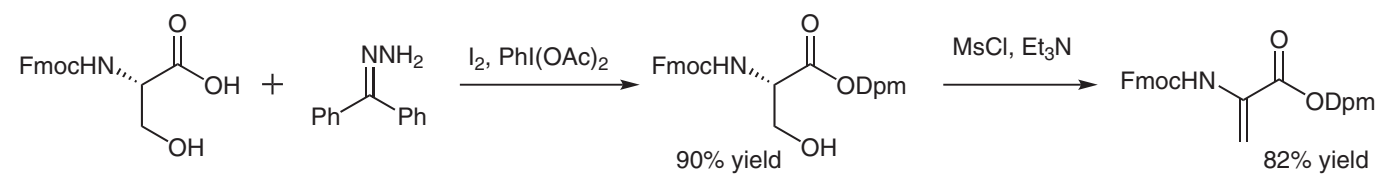

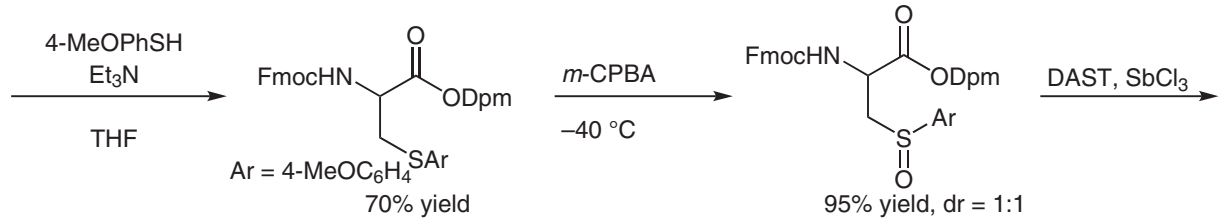

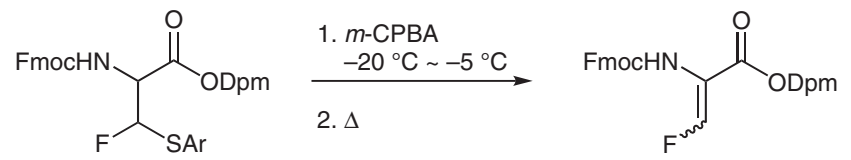

$70 \%$ yield, $\mathrm{dr}=1: 1 \quad 47 \%$ yield, $Z / E=1: 1$

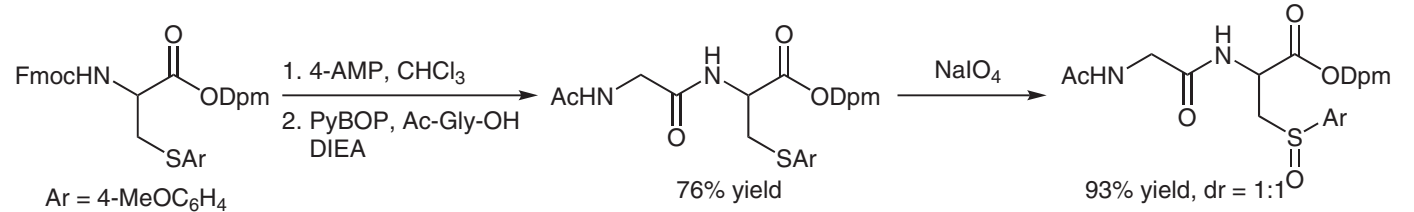

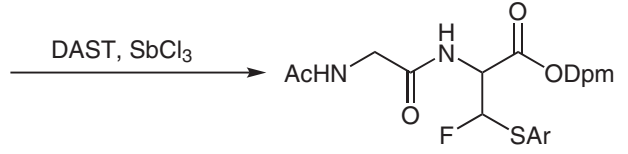

$65 \%$ yield, $\mathrm{dr}=1: 1$

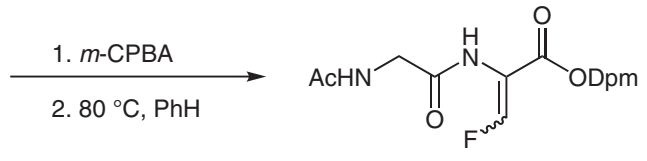

$57 \%$ yield, $Z$ ZIE $=1: 1$
Significance: Dehydroalanine moieties occur abundantly as scaffolds in natural products. Also, fluorine-substituted compounds have received increasing attention due to their small steric bulk and their lipophilicity. The authors developed a strategy for the synthesis of fluorine-substituted dehydroalanines.
Comment: (E)-And (Z)-fluorodehydroalanines were synthesized from $\mathrm{N}$-protected serines through a fluoro-Pummerer rearrangement. Moreover, this methodology can be applied in dipeptide synthesis. 